\title{
O dever da caridade aos pobres: circulação de excedente, furto e a construção da noção de propriedade no interior da Ordem dos Frades Menores a partir das Legenda Maior e da Vita Secunda.
}

Douglas de Freitas Almeida Martins ${ }^{1}$

Resumo: Este artigo tem por objetivo propor uma análise dos textos hagiográficos de São Boaventura - Legenda Maior - e Tomás de Celano Vita Secunda - como modelos dotados de valores idealizados pela Ordem dos Frades Menores em sua inserção na vida material nos espaços urbanos da Península Itálica em princípios do século XIII. Para realizar tal análise foi necessário utilizar conceitos que evitem a abordagens singulares e maniqueístas, que destacam a vida material como um domínio social apartado das demais experiências históricas. Os textos hagiográficos foram interpretados com o auxílio das formulações teóricas do Primitivismo Econômico. O discurso acerca do pauperismo não será tomado como uma atitude antieconômica, mas sim como mecanismo essencial da conduta dos frades minoritas frente a temas como propriedade, circulação de excedente e o furto.

Palavras-chaves: Hagiografia - Pauperismo - Primitivismo Econômico

Abstract: The a imo $f$ this article is to propose an analysis of the hagiographic texts of St. Bonaventure - Major Legend - and Thomas of Celano - Vita Secunda - as models end owed with idealized values by the Order of the Friars Minor in their insertion in material life in the urban spaces of the Italic Peninsula in principles of the thirteenth century. In order to carry out such an analysis it was necessary to use concepts that escaped singular and Maniche an approaches, which highlight material life as a social domain that is separated from other historical experiences. The hagiographic texts were

${ }^{1}$ Doutorando do Programa de Pós Graduação em História da Universidade Federal de Mato Grosso. $\mathrm{O}$ artigo aqui apresentado é fruto das reflexões desenvolvidas durante a construção da dissertação de mestrado cujo titulo é $O$ pauperismo como equilíbrio econômico: as hagiografias e as engrenagens da materialidade na ordo fratrumminorum (1228-1263) defendido junto ao Programa de Pós Graduação em História da UFMT defendido em 2015. "O presente trabalho foi realizado com apoio da Coordenação de Aperfeiçoamento de Pessoal de Nível Superior - Brasil (CAPES) Código de Financiamento 001."This study was financed in part by the Coordenação de Aperfeiçoamento de Pessoal de Nível Superior - Brasil (CAPES) - Finance Code $001 "$.

Revista Vernáculo n. ${ }^{\circ} 43$ - primeiro semestre/2019

ISSN 2317-4021 
interpreted with the a idol the theoretical formulations of Economic Primitivism. The discourse on pauperism will not be taken as an uneconomical attitude, but rather as an essential mechanism for the conduct of the minority friar son issues such as property, circulation of surplus and theft.

Keywords: Hagiography - Pauperism - Economic Primitivism

Este artigo analisa as hagiografias ${ }^{2}$ minoritas escritas ao longo do século XIII como detentoras de um ethos econômico. Elas configuram-se como portadoras de valores idealizadas pela Ordem dos Frades Menores e tornam-se modelos para o reconhecimento das funções que a Ordem poderia assumir perante a sociedade em expansão material das cidades italianas medievais.

Nascido no século XIII, no coração da Península Itálica primeiramente como um movimento laico - mas que, rapidamente cresceu, expandiu e institucionalizou-se - o franciscanismo se tornou um dos movimentos espirituais ${ }^{3}$, culturais e sociais de maior difusão e transcendência na História da Igreja e da espiritualidade. A posição de

${ }^{2}$ Compreendo hagiografia enquanto um discurso edificante que tem por objetivo atuar sobre a conduta de seus receptores. Não se trata de uma biografia, pois não tem por pretensão "informar" o passado, mas sim de formar seus "receptores" (MIATELLO, 2013). Para Thomas Head, o hagiógrafo não tinha como objetivo escrever uma recordação biográfica do santo, mas apresentá-lo como um modelo de conduta cristã, como a encarnação de um modelo ético. De acordo com Hellfman, trata-se de uma finalidade distinta do que se propõe a biografia Ainda segundo Borbolla (2002), mesmo que possa ser utilizada como fonte para o estudo do passado, a obra hagiográfica apresenta ao pesquisador um texto dotado de outras finalidades: moralistas, dogmáticas, sermonísticas, etc.

${ }^{3}$ São Francisco, segundo Martino Conti, agia muito mais como uma espécie de "imitador" de Cristo, seguindo de perto suas ações e comportamentos, do que um apóstolo. Sua atitude se aproximava da Sagrada Escritura sendo caracterizada pelo espírito de fé, de humildade e de amor. "Segundo São Francisco, o verdadeiro discípulo de Cristo renega-se a si mesmo" (CONTI, 2004, p.137).

Revista Vernáculo n. ${ }^{\circ} 43$ - primeiro semestre/2019

ISSN 2317-4021 
Francisco ${ }^{4}$ é reveladora: em um período de inquietação em todos os níveis, e do rápido surgimento e desenvolvimento de formas de contestação à vida dos clérigos e monges, o santo de Assis procurava evitar toda a confusão com movimentos com os quais o seu podia ser confundido. Como um leigo, será no evangelho de Cristo que ele encontrará o seu modo de vida ${ }^{5}$.

A historiografia clássica e que comporta nomes como Paul Sabatier, Jacques Le Goff, Martino Conti, dentre outros, legou a imagem de uma fraternitas e posteriormente de uma Ordo que adotou uma postura não apenas de distanciamento, mas também de combate à vida material, de forma que o discurso acerca do pauperismo é um discurso de renuncia a materialidade.

Esta imagem foi desenhada a partir da leitura dos textos hagiográficos escritos por Tomás de Celano e São Boaventura, frades minoritas, na década de 1220 e 1260, respectivamente. No entanto, proponho uma leitura sob um prisma pouco privilegiado pelos historiadores. Os textos hagiográficos foram interpretados com o

${ }^{4}$ A imagem criada pelos historiadores acerca da Ordem e de Francisco de Assis reflete personagens que abalaram e sacudiram a religião, a civilização e a sociedade medieval, desempenhando papel decisivo no impulso de novas ordens medicantes, por meio de uma revolta sem niilismo, como defende Jacques Le Goff, no prefácio da biografia do santo; Francisco e sua experiência religiosa são retratados por Chiara Frugoni (2011) como marcos de uma renovação da espiritualidade no interior da Cristandade ou; ainda como precursores de uma revolução laica no século XIII como atesta AndreVauchez (1995).

5 Ver ainda: (BASCHET, 2006); (LE GOFF, 2010); (VAUCHEZ, 1995); (DUBY, 1992). 
auxilio das formulações teóricas do Primitivismo Econômico ${ }^{6}$ e os indícios e pequenos detalhes contidos na narrativa santoral revelaram um ethos idealizado a respeito da inserção dos frades na materialidade urbana de princípios do século XIII. Deste modo, o presente artigo esta embasado na acepção de que as hagiografias foram veículos de transmissão de um status específico, o qual, tendo o personagem Francisco de Assis como um elemento central, articulava os ideais do pauperismo $^{7}$, da caridade e da fraternidade como meios de inserção dos frades nos domínios chamados econômicos - e não da negação do mesmo.

Por fim, é válido também destacar que o presente artigo é devedor das contribuições teóricas do historiador André Miatello, que em sua tese de doutoramento Retórica religiosa e cívica na Itália do século XIII: a composição e o uso das hagiografias mendicantes nas políticas de paz (2010) se propõem a analisar o fenômeno hagiográfico e os quadros políticos da sociedade italiana no século XIII. Partindo de uma abordagem que esta alinhada com os pressupostos teóricos da Nova História Política, o autor trata a hagiografia como portadora de

${ }^{6}$ Convencionou denominar como sendo o Primitivismo Econômico, uma escola de pensamento econômico que começou a tomar corpo na Alemanha na segunda metade do século XIX. Reunindo economistas, historiadores, sociólogos e posteriormente antropólogos, tais intelectuais foram os primeiros a criticar a simples transposição de termos da moderna concepção de economia para sociedades anteriores ao advento da industrialização. Em outras palavras, era necessário encontrar outras categorias para denominar as práticas ditas econômicas anteriores ao século XVIII.

${ }^{7}$ Compreendo o pauperismo para além de sua definição baseada em um discurso de extrema pobreza. O pauperismo na análise que pretendo realizar é um discurso que se configura como um mecanismo econômico.

Revista Vernáculo n. ${ }^{\circ} 43$ - primeiro semestre/2019

ISSN 2317-4021 
valores promulgados pelos minoritas acerca da transformação moral da sociedade e que estão associadas a uma retórica especifica, expressando uma imagem idealizada do espaço urbano. Esta abordagem proposta por Miatello é fundamental e importante não apenas para este artigo, mas também para renovação dos estudos acerca da Ordem dos Frades Menores. Fim de orientação para os leitores, o texto esta dividido a partir de uma breve apresentação das fontes documentais e complementado em seguida por uma análise teórica, seguida por uma conclusão.

\section{I}

São Boaventura, sétimo ministro-geral da Ordem dos Frades Menores, escreveu na década de 1260 duas obras hagiográficas a respeito da obra e vida de Francisco de Assis, líder minorita. Tomadas como narrativas oficiais, substituindo as vitas antigas, elas traziam elementos imaginados da vida do santo de Assis. Francisco é o personagem retratado na narrativa e contém diversos episódios idealizados protagonizados pelo mesmo. Trarei um episódio para exemplificar a abordagem.

Boaventura possibilita nos imaginar um Francisco ${ }^{8}$, que ao retornar de Sena, vestido com um manto por causa de uma enfermidade,

8 A fonte de inspiração deste episódio é o próprio Celano (IN: FONTES FRANCISCANAS E CLARIANAS, p. 358): "Noutra ocasião, quando voltava de Sena, encontrou um pobre; e o santo disse ao companheiro: 'Irmão, é necessário que restituamos o manto ao pobrezinho, pois a ele pertence. Recebemo-lo de empréstimo

Revista Vernáculo n. ${ }^{\circ} 43$ - primeiro semestre/2019

ISSN 2317-4021 
encontra um pobre. Ao olhar e constatar o estado miserável em que se encontrava o homem, o santo disse ao companheiro": "é preciso que restituamos o manto a este pobrezinho, pois é dele. Recebemo-lo de empréstimo até que acontecesse encontrarmos alguém mais pobre" (IN: FONTES FRANCISCANAS E CLARIANAS, 2008, p. 602). O frade que o acompanhava, considerando a necessidade física no qual encontrava Francisco - por causa de sua doença - resistia à ideia de prover o outro com o manto, esquecendo-se de si mesmo. Francisco disse: "Se eu não der o que visto ao mais necessitado, penso que se me deva imputar como furto pelo grande Esmoler" (IN: FONTES FRANCISCANAS E CLARIANAS, 2008, p. 603). Por esta razão, em relação a todas as coisas que lhe eram dadas para aliviar as dores do corpo, ele estava acostumado a pedir licença aos doadores para poder distribuí-las licitamente, se encontrasse alguém mais pobre.

até acontecer que encontremos alguém mais pobre' [...] Disse-lhe o santo: 'Não quero ser ladrão; ser-nos-ia imputado como furto, se não dermos aos mais necessitados". Este trecho é revelador: as hagiografias reproduzem um discurso em comum. Um discurso que desde os primeiros anos se faziam presente no interior da Ordem.

${ }^{9}$ Accidit semel, ut eidem redeunti de Senis pauper quidam occurreret, cum occasione infirmitatis super habitum palliolo quodam esset amictus. Cuius miseria oculo clementi conspecta: "Oportet", inquit ad socium, "ut reddamus mantellum pauperculo isti, nam ipsius est. Mutuo enim ipsum accepimus (cfr. Luc 6,34), donec pauperiorem invenire contingeret". Socius autem pii patris necessitatem considerans, pertinaciter obsistebat, ne provideret alii, se neglecto. At ille: "Pro furto mihi", ait, "reputo a magno Eleemosynario imputandum, si hoc quod fero, non dedero magis egenti". Propterea de omnibus, quae sibi dabantur ad necessitatem corporis relevandam, solitus erat a dantibus licentiam petere, ut licite posset, si magis egenus occurreret, erogare. PELTIER, A.C. S. R. E. S. Bonaventurae Opera Minorum. Paris: L. Vivès, 1868 , p. 320.

Revista Vernáculo n. ${ }^{\circ} 43$ - primeiro semestre/2019

ISSN 2317-4021 
Na cena narrada, Francisco ao se deparar com um pobre sente a obrigação de restituir o manto ao necessitado para não incorrer em furto pelo "grande Esmoler" (IN: FONTES FRANCISCANAS E CLARIANAS, 2008, p. 603). Gostaria de destacar uma palavra em especial: furto. No dicionário Houaiss o ato de furtar aparece como um "roubo de pouca monta, praticado às escondidas e sem violência." Seu ato cruza a fronteira do que é considerado licito e fere o direito a propriedade de um dado bem. Não se trata aqui do direito a uma propriedade privada. Mas tal ato configura uma transgressão de uma norma estabelecida e que fere a legitimidade e o pertencimento de um dado bem.

Em um estudo muito interessante sobre o tema, o professor Dr. Marcelo Cândido (2014) propôs algumas argumentações - que apesar de serem voltadas para os séculos VI ao VIII - que podem lançar luz sobre o problema da propriedade e do roubo na Idade Média. Ao consideramos o furto ${ }^{10}$ como um desvio de normas é necessário atentarse que elas possuem um reconhecimento e uma aceitação social. A aceitação das normas significa "não apenas uma mudança de comportamento dos atores sociais, ela implica também no reconhecimento por parte dos mesmos de que as coisas e as pessoas assumem formas distintas daquelas que eram as suas antes que as

${ }^{10}$ Conforme ressalta o professor Marcelo Cândido (2014, p. 20-30), as hagiografias medievais, frequentemente, não distinguem as noções de roubo e furto, tal como os códigos de direito do mundo moderno. Portanto, ao longo deste capítulo recorreremos aos dois termos como intercambiáveis. 
normas se projetassem sobre elas" (CANDIDO, 2014, p. 26). Em outras palavras, buscar a efetivação das normas contra o roubo no mundo franco é um exercício pouco proveitoso. Ao deslocar o problema para a questão de fabricação dos sujeitos através da norma, Marcelo Cândido, permite pensar que a fronteira entre coisas e pessoas é cambiante e passível de significações diversas.

“As normas não se dirigem à sociedade, mas são parte integrante da construção social" (CANDIDO, 2014, p. 26). É o que ocorre quando nos referimos ao período chamado de medieval e percebemos que as normas não são valores jurídicos em sentido estrito, mas, sobretudo, valores sociais. As normas são construções sociais - que podem ser veiculadas, por exemplo, em textos hagiográficos e não somente em tratados jurídicos - e não simplesmente instrumentos que constroem a realidade.

Tendo esta argumentação como fundamento conceitual, retornemos ao relato de Boaventura. Francisco caminharia na direção oposta à norma pré-estabelecida - isto é, à obrigação de dar aos pobres o que lhe é direito - caso não entregasse o bem (a veste) ao mais necessitado. Embora, socialmente, acumulasse diversas conotações, o manto surge no relato marcado por uma significação forte. O contexto permitiria ressaltar o valor de utilidade - sua serventia para aquecer e proteger do frio, por exemplo - ou de distinção social - como um símbolo de uma posição religiosa ou mesmo aristocrática específica. Mas, na hagiografia, o manto é, acima de tudo, parte integrante de uma 
opção de vida marcada pela pobreza: a necessidade de dar e agir de acordo com a caridade. O objeto, portanto, surge como elemento constituinte dos modos de agir esperados dos sujeitos - é a norma agindo na construção social, conforme ressaltou Marcelo Cândido.

$\mathrm{Na}$ continuação do trecho narrado, Boaventura informa que o santo não poupava absolutamente nada, fossem mantos, túnicas ou livros da obrigação de doar aos pobres e cumprir o dever da piedade. Não fazê-lo seria incorrer na prática de furto. Descumprir a caridade é equivalente a furtar. Diante desta ênfase, gostaria de ressaltar o aspecto que me chama atenção nesta caracterização: ela é um exemplo de reciprocidade. Aqui, mais uma vez, é necessária uma pausa, para explicar o argumento. Ela é importante para que eu conceitue aquilo que entendo como relação recíproca. Irei recorrerei aos fundamentos teóricos de Karl Polanyi.

De acordo com o antropólogo húngaro, para que um grupo decida organizar suas relações com base em movimentos recíprocos, deve "se dividir em subgrupos simétricos cujos membros pudessem identificar uns aos outros como tais" (POLANYI, 2012, p. 87). Os membros de um grupo denominado como "A" podem estabelecer relações de mutualidade com seus correspondentes do grupo "B", e vice-versa. Um movimento recíproco desloca a ênfase do componente utilitário, da "vantagem egoísta, para a experiência amável e gratificante que flui dos contatos de vizinhança mutualmente honoríficos com aqueles a quem ligamos em relações especificas" (POLANYI, 2012, p. 
110). Um movimento com esta conotação pressupõe identificação, afeição, admiração e, por vezes, medo. É por isso que Polanyi utiliza constantemente o termo solidariedade: o comportamento adequado é o da equidade e da consideração.

A origem desse movimento não é econômica: "enquanto o nosso senso de justiça se expressa em termos de punição e recompensa, os movimentos recíprocos de bens se expressam em termos de dádiva e contra dádiva" (POLANYI, 2012, p. 87). O hábito de ofertar algum presente não vem acompanhado, necessariamente, de uma negociação ou uma barganha. São precisamente estes sentimentos que desestimulam qualquer manifestação de interesse econômico pessoal na relação. Isso não significa afirmar que as sociedades onde se partilham tais relações não havia nenhum substantivo econômico -em situações assim, os homens não estão desprovidos de motivações econômicas.

Antes de identificá-lo com uma dinâmica de produção e expansão da riqueza, o adjetivo "econômico" deve ser fixado a uma definição mais historicamente abrangente: nomear certas racionalidades de reprodução da vida material. Segundo Karl Polanyi, tal formulação permite evitar uma série de excessos: o importante, segundo ele, é entender a economia neste sentido substantivista. É precisamente este o significado econômico do qual irei utilizar como conceito de análise: a prática "econômica" está onde podem ser detectados padrões de uma interação institucionalizada com o meio natural, visando fornecer os

Revista Vernáculo n. ${ }^{\circ} 43$ - primeiro semestre/2019

ISSN 2317-4021 
meios para satisfazer as necessidades materiais de um grupo (POLANYI, p. 64, 2012).

Um dos aspectos centrais a ser discutido nesta definição de economia é a noção de propriedade. Antes de qualquer coisa é necessário definir o que a palavra coloca em jogo. Esta não é uma tarefa fácil. De acordo como Richard Pipes (2001), existiriam duas formas de compreender o que é uma propriedade: uma conceitual e outra institucional. O significado de ambas altera-se ao longo do tempo, revelando a própria historicidade do termo: é possível perceber continuidades e rupturas desta noção ao longo da história. Contudo, algo parece ser consensual: "a história de todas as sociedades, por um lado, da mais primitiva a mais avançada, revela a universalidade do direito à propriedade" (PIPES, 2001, p. 23).

Qualquer mudança de atitude em relação à propriedade pode ser explicada pelo comportamento político ou econômico. E não são poucos os argumentos que legitimam o direito a propriedade, como afirma o mesmo autor (PIPES, 2001): sejam políticos (quando promovem a estabilidade e limitam as ações de governo), sejam eles morais ou psicológicos (quando definem a legitimidade a partir de parâmetros culturais relativos, por exemplo, às formas de reconhecimento de diferentes tipos de trabalho ou de ideais de igualdade, autoestima, etc), sejam econômicos (ao sustentarem que a propriedade é o meio mais eficiente de produzir riqueza).É um problema de muitas faces sociais. 
Nossa moderna concepção de propriedade instaurou uma ruptura entre aquilo que é "meu" e aquilo que é "seu". Isto nem sempre foi desta forma: as concepções de um passado mítico no qual as desigualdades sociais inexistem é um exemplo. $\mathrm{O}$ autor é ainda mais enfático: "nenhuma sociedade existiu sem algum tipo de propriedade" (PIPES, 2001, p. 25). Na Antiguidade, Platão e Aristóteles defendiam pontos de vistas diferentes no que se refere à existência de propriedades. Na Idade Média a ideia de propriedade foi alvo de intensos debates: se as primeiras comunidades cristãs aceitavam sua existência, a partir do momento em que se expandiram, foi necessário encontrar um meio-termo entre o ideal apostólico de um despojamento do mundo e a instalação das comunidades na realidade mundana - o que pode ser encontrado nas obras de Santo Agostinho, por exemplo.

Talvez o autor mais paradigmático para a discussão da noção de propriedade nos estudos medievais seja o historiador Alain Guerreau. Em sua obra Futuro de um passado (2002), Guerreau chamou atenção para dois conceitos fundamentais para uma análise da realidade medieval: a ecclesia e dominium. A título dos objetivos específicos deste artigo, focalizarei a noção de dominium.

Apresentando uma critica feroz aos pressupostos do Iluminismo e Liberalismo - que teriam inventado e difundido categorias analíticas completamente estranhas à Idade Média -, Guerreau insiste em recuperar o termo dominium como modo de preservar certas especificidades da noção de propriedade no mundo medieval e sua 
manifestação política. Dominium não é sinônimo de propriedade. Aos olhos do medievalista, esta não é tratada como instrumento jurídico, algo sobre o qual os medievais poderiam vivenciar ou falar como um objeto destacado como algo em si ou uma relação auto referencial. Os homens e mulheres que viveram há cerca de mil anos experimentaram a propriedade, mas como uma dimensão do dominium, isto é, uma realidade social maior, abrangente e intercambiável com diversas práticas coletivas. Tal lógica era "uma forma específica de dominação bífida, concernindo ao mesmo tempo os homens e as terras" (IN: LE GOFF \& SCHIMIDT, 2006, p. 440). Trata-se de uma relação social que envolvia dominantes e dominados em que os primeiros exerciam simultaneamente um poder sobre os homens e sobre a terra.

De toda esta argumentação eis o que pretendemos reter: no universo econômico da sociedade medieval, eminentemente substantivista, as relações de propriedade eram parte das realidades coletivas - embora fossem experimentadas no bojo de relações mais abrangentes (o dominium), sobre as quais, em várias circunstâncias, predominavam não o valor utilitário, mas, como dissemos acima, certas conotações que muitos chamariam de "religiosas", já que pressupõem identificação, afeição, admiração e, por vezes, medo. Dito isto, voltemos ao exemplo.

Esta explanação conceitual realça como o relato hagiográfico está marcado por um conceito de propriedade bem definido. Não se trata de entender a propriedade como um fato ou acontecimento, mas 
como valor legítimo. É possível questionar se de fato as vestes narradas existiram ou se pertenceram à imaginação do hagiógrafo. Podemos até mesmo duvidar de que o próprio episódio tenha ocorrido. Mas isso não é decisivo para a argumentação que desenvolvo. O importante, para o ponto de vista que desejo destacar, é que está em jogo uma ideia socialmente produzida e cuja aceitação era defendida: um valor ou simplesmente uma concepção de propriedade.

Trata-se de uma concepção da propriedade como realidade humana coletiva. O seu marcador discursivo é a noção de furto. Não cumprir a caridade significa, no relato, lesar uma posse coletiva dos bens: os "bens pertencem aos pobres". À medida que os bens circulam entre os homens, através da caridade e da reciprocidade, retê-los aparece como algo legítimo - desde que seja o grupo o detentor. Não se trata de propriedade individual: a qual, por sinal, é estigmatizada nos relatos hagiográficos franciscanos. Mas, por outro lado, não se trata igualmente de um bem que pertence a Deus, como se santificado ou divinizado como "propriedade divina". Quem subtraí à caridade comete um furto contra os homens - neste caso, os pobres. A caridade, forma de reciprocidade, faz com que a prática de reter o bem não seja pessoal ou estática: o bem não deve permanecer em um lugar, fixo, ou ser visto nas mãos de alguém. Ele deve circular, mover-se, ser repassado conforme se reconhecem as necessidades. A narrativa destaca uma posse dinâmica dos bens, que devem circular não como "vantagem egoísta", mas como "experiência amável e gratificante que flui dos 
contatos de vizinhança mutualmente honoríficos com aqueles a quem ligamos em relações especificas" (POLANYI, 2012, p. 110).

Visto por outro ângulo, este mesmo caso poderia ser definido assim: Francisco surge na narrativa legitimando uma posse doméstica, partilhada no âmbito da família - conforme ensinava uma antiga tradição. Neste caso, a noção de posse e circulação de bens está intimamente ligada à ideia de usufruto fraternal, máxima da oikonomia antiga. A equação é romana. Foi estudada pela autora Kristina Sessa (2013, p. 174-188) para demonstrar a inserção do cristianismo na vida imperial através da influencia que os bispos de Roma exerciam junto à família e administração do oikos (antiga designação para a economia). Em seu livro, The Formationof Papal Authority in Late Antiqueltaly: Roman Bishops and the Domestic Sphere, Sessa utiliza largamente as categorias e expressões que identificavam o papel de ordenamento material e controle jurisdicional exercido por um pater familias. A expressão latina nomeava uma figura masculina que personificava relações coletivas: não se trata de um indivíduo e da afirmação de suas prerrogativas particulares ou soberanas, mas do ponto de convergência de necessidades, demandas e obrigações de um grupo formado por consanguíneos, criados e escravos. O pater familia dava voz aos direitos e deveres de um grupo.

A afirmação a que pretendo chegar é esta: Francisco figura na hagiografia como um pater familia, cuja atuação, ao assegurar a circulação dos bens através da caridade e dos deveres para com a 
pobreza, legitima a posse destes bens pelo grupo representado por ele. É esta realidade que surge marcada através do emprego da noção de furto: furtar aos pobres é deslegitimar a circulação e o usufruto do bem pela família.

A ideia de furto reaparece nas hagiografias. É tema recorrente na própria obra de São Boaventura e também na produção hagiográfica de outro frade, Tomás de Celano. Entre 1244 E 1247, o ministro geral da Ordem Minorita, Crescentius de Jessis, encomendou junto à Celano a Vida segunda que reflectia a evolução das perspectivas oficiais sobre o santo nas décadas seguintes à sua morte. Essas duas narrativas são agora comparadas. Retomemos a clássica passagem no qual Francisco compara o dinheiro como algo do demônio, narrada pelos dois hagiógrafos. Vejamos os seguintes relatos:

Celano - Vida segunda

"Passando uma vez o homem de Deus com um companheiro pela Apúlia perto de Bari, encontrou no caminho uma grande bolsa, que na linguagem dos comerciantes se chama funda, inchada de moedas. É advertido pelos irmãos e tentado com insistência a que se apanhe a bolsa do chão e se distribua o dinheiro aos pobres. Exalta-se a compaixão para com os necessitados, e elogiase a misericórdia na distribuição do dinheiro. O santo recusa-se terminantemente a fazê-lo e afirma que é astucia do demônio. Diz: 'Não e permitido, filho, tomar coisas alheias; dar coisas alheias não merece glória, mas é pecado que merece castigo.' Afastam-se do lugar, apressam-se em terminar a viajem começada. Mas o irmão ainda não ficou quieto, iludido por falsa piedade; continua ainda a sugerir a transgressão. O santo consente em voltar ao lugar, não para cumprir o desejo do irmão, mas para mostrar ao tolo o mistério divino. Chama um jovem que se achava sentado sobre um poço a beirado caminho para que, pela boca de duas ou três testemunhas, se manifeste o segredo da

Revista Vernáculo n. ${ }^{\circ} 43$ - primeiro semestre/2019

ISSN 2317-4021 
Trindade. Tendo os três retornado a funda, vêem-na recheada de moedas. O santo proíbe a qualquer um deles de se aproximar-se, para que por força da oração, seja denunciada a falácia do demônio. Retirando-se dali o quanto é um tiro de pedra, dedica-se a sagrada oração. Voltando da oração, manda o irmão levantar a bolsa que, enquanto ele rezava, continha uma cobra em vez de dinheiro [...] E disse-lhe o santo: 'Irmão, o dinheiro para nos, servo de Deus, nada mais é do que o demônio e uma cobra venenosa". 11

Boaventura - Legenda Maior

"O pobre de Cristo é admoestado e tentado com insistência pelo companheiro a que se tome a bolsa do chão e se de o dinheiro aos pobres. O homem de Deus, afirmando que havia uma armadilha do demônio na bolsa encontrada e que o irmão o aconselhava não uma coisa de mérito, mas de pecado, a saber, surrupiar e das coisas alheias. Afastam-se do lugar e apressam a caminhada iniciada. Mas o irmão ainda não fica tranquilo, iludido por falsa piedade,

${ }^{11}$ Transeunte aliquando viro Dei (cfr. Iudc 13,6.8) cum socio per Apuliam prope Barum, invenit in via bursam magnam, denariis tumescentem, quae funda negotiatorum vocabulo nuncupatur. Monetur a socio sanctus et instanter inducitur, ut bursa tollatur e terra, et pecunia pauperibus erogetur. Attollitur pietas in egenis, et in erogatione ipsius misericordia commendatur. Recusat sanctus id penitus se facturum, et commentum affirmat fore diaboli."Non licet", inquit, "fili, alienum auferre; peccati poena, non meriti gloria est aliena donare". Recedunt de loco, festinant iter perficere coeptum (cfr. Iudc 19,14). Sed nondum quiescit frater, vacua pietate delusus; addit adhuc (cfr. 2Re 5,22) praevaricationem suggerere. Acquiescit sanctus redire ad locum, non ut fratris impleat votum (cfr. Num 15,8), sed ut fatuo divinum ostendat mysterium (cfr. Dan 2,29). Advocat iuvenem quemdam, qui supra puteum sedebat (cfr. Ioa 4,6) in via, ut in ore duorum vel trium testium (cfr. Mat 18,16) Trinitatis clareat sacramentum. Reversis iam tribus ad fundam, denariis eam tumidam vident. Prohibet sanctus quemquam illorum appropinquare, ut orationis virtute daemonis prodatur fallacia.Recedens inde, quantum iactus est lapidis (cfr. Luc 22,41), orationi sacrae incumbit.Rediens ab oratione, iubet fratrem levare bursam, quae, ipso exorante, pro pecunia colubrum continebat. Tremit frater et stupet, et nescio quid iam praesentiens, alia quam solito animo volvit. Timore tandem obedientiae sanctae dubietatem abigens cordis, bursam manibus capit. Et ecce serpens non modicus de bursa exsiliens, diabolicam deceptionem fratri monstravit. Et ait sanctus ad eum: "Pecunia servis Dei (cfr. Gen 50,17), o frater, nihil aliud est quam diabolus et coluber venenosus". D'ALENÇON, Edouard. Francisci Assisensis: vita et miracula, additis opusculis liturgicis, auctore Fr. Thoma de Celano. Roma, Desclée: 1906, p. 222-223.

Revista Vernáculo n. ${ }^{\circ} 43$ - primeiro semestre/2019

ISSN 2317-4021 
molestando o homem de Deus, como se este não se preocupa-se em aliviar a penúria dos pobres. Finalmente, o homem cheio de mansidão aquiesceu em voltar o lugar, não para cumprir a vontade do irmão, mas para colocar a descoberto a fraude diabólica. Retornando, portanto, a sacola com o irmão e com um jovem que estava na estrada, tendo feito a oração, ordena ao companheiro que a levante. A tremer, o irmão fica estupefato, pressentindo já o monstro diabólico [...] e eis que uma serpente não pequena, saltando da bolsa e ao mesmo tempo desaparecendo subitamente com ela, mostrou ao irmão o engano do demônio"12

Os dois relatos associam o dinheiro a uma obra demoníaca e o comparam a uma cobra. Vou me deter à narrativa de Celano. No limite do discurso hagiográfico aparece a noção de posse. Nos dois casos, a bolsa (ou funda) de dinheiro não deveria ser tocada por que pertencia a alguém. Há uma relação de propriedade e ela não deveria ser violada. Esta era a artimanha do demônio: induzir os frades a, sob a aparência de caridade, infringir a norma social da propriedade. Mas é preciso esclarecer: o que significa dizer "no limite do discurso hagiográfico"?

12 Transiens autem quodam tempore vir Dei cum socio per Apuliam iuxta Barum, invenit in via bursam magnam, quasi plena esset denariis, tumescentem, quam usitato vocabulo fundam appellant. Monetur a socio pauper Christi et instanter inducitur, ut bursa tollatur e terra, et pecunia pauperibus erogetur. Renuit homo Dei, commentum affirmans fore diaboli in bursa inventa, et fratrem non suadere rem meriti sed peccati, aliena scilicet surripere ac donare. Recedunt de loco, festinant iter perficere coeptum. Sed nondum quiescit frater, vacua pietate delusus, virum Dei molestans, quasi qui de relevanda pauperum penuria non curaret. Acquievit tandem vir mitis redire ad locum, non ut fratris voluntatem perficeret, sed ut detegeret diabolicam fraudem. Reversus ergo ad fundam cum fratre et iuvene quodam, qui erat in via, oratione praemissa, iubet socio illam levare. Tremefactus frater obstupuit, diabolicum iam praesentiens monstrum; propter obedientiae tamen sanctae mandatum dubietatem abigens cordis, manum extendit ad bursam. Et ecce, serpens non modicus, de bursa exsiliens simulque cum ipsa subito evanescens, diabolicam deceptionem fratri monstravit.Hostilis itaque versutiae deprehensa fallacia, dixit vir sanctus ad socium: "Pecunia servis Dei, o frater, nihil aliud est quam diabolus et coluber venenosus. PELTIER, A.C. S. R. E. S. Bonaventurae Opera Minorum. Paris: L. Vivès, 1868, p. 316.

Revista Vernáculo n. ${ }^{\circ} 43$ - primeiro semestre/2019

ISSN 2317-4021 
Neste caso quer dizer que o discurso aciona uma figura para além da qual as normas e valores não se aplicam, estariam suspensos ou mesmo subvertidos por completos. Trata-se da figura que assinala o limite da vigência dos valores narrados: precisamente a figura do demônio.

Sob os seus diversos nomes e aparências multiformes, o Diabo Satã e seus demônios - é seguramente uma das figuras mais importantes dos universos culturais do Ocidente medieval: "oponente das forças celestes, tentador do justo, inspirador dos ímpios e dos pecadores, verdugo dos condenados, ele é onipresente e seu terrível poder se faz sentir em todos os aspectos da vida e das representações mentais medievais" (LE GOFF \& SCHMITT, 2006, p. 319); “A história do Diabo confunde-se com a história do próprio Cristianismo [...] Era necessária para a coletividade cristã à existência e a encarnação do mal" (NOGUEIRA, 2002, p. 20).Quase totalmente ausente das imagens cristãs até o século IX, é a partir do ano 1000 que ele passa a ocupar um lugar de destaque nos imaginários (DELUMEAU, 1993, p. 95). "Sua primeira referencia é dos livros apócrifos da tradição judaica, a saber, o Livro de Henoc (século II a. C)" (LE GOFF \& SCHMITT, 2006, p. 321). Os nomes que o designam são vastos e variam de acordo com a matriz religiosa.

Desde a queda dos anjos, a "Revolta de Lúcifer", até o desfecho escatológico anunciado pelo Apocalipse, Lúcifer surge como a figura que encarna o limite das ações humanas no terreno da reta conduta. Por causa do pecado original, o homem é submetido ao poder do Diabo, que 
possui sobre ele um verdadeiro direito: “contudo, Satã é príncipe somente dos pecadores, pois Cristo resgatou com seu sacrifício o direito que o Diabo tinha sobre a humanidade" (LE GOFF \& SCHMITT, 2006, p. 323). O demônio, inclusive, está ligado à noção de individualidade, visto que a crença na existência de diabos pessoais era forte na Idade Média (BASCHET, 1993). Entretanto, no relato a relação de valores instaurada é essa: a tentação diabólica consiste em violar a noção de propriedade.

Em outro exemplo, descrito décadas após Celano, São Boaventura nos apresenta uma situação que expressa valores semelhantes. Francisco aparece na narrativa proferindo um sermão sobre a pobreza e repetindo aos irmãos o seguinte dito evangélico: "as raposas têm suas tocas, e os pássaros do céu seu ninho, mas o filho do homem não tem onde reclinar sua cabeça"13 (IN: FONTES FRANCISCANAS E CLARIANAS, 2008, p. 593). Através destas palavras, ensinava seus companheiros a construir casas "pobrezinhas, à maneira dos pobres, nas quais habitassem como peregrinos e forasteiros, não como se elas fossem próprias, mas alheias" (IN: FONTES FRANCISCANAS E CLARIANAS, 2008, p. 593).

Como o exemplo anterior, este trecho demonstra: há uma noção de propriedade em questão. Não uma propriedade individual, mas uma propriedade que se reconhece como humana, coletiva, ou "alheia". A hagiografia explora um conceito de propriedade muito particular. Quase

${ }^{13}$ Mateus Cap. 8 Versículo 20.

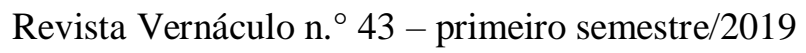

ISSN 2317-4021 
como se em cada um destes momentos estivesse em jogo uma parcela da identidade da Ordem para definir qual noção de propriedade é válida. A propriedade surge no trecho como um modo de usar, uma maneira de reter ("à maneira dos pobres") - não como uma categoria aplicada ao indivíduo ("não como se fossem próprias").

A posse, da mesma forma que na escrita hagiográfica de Celano, é legitima quando coletiva. A propriedade é autorizada, pois há uma medida do seu exercício - ainda que a medida se aplique ao "alheio". Em uma narrativa hagiográfica, perpassada por referenciais sagrados, a ideia de propriedade está nas entrelinhas. Não é Cristo, por exemplo, quem autoriza a posse, mas sim as figuras dos peregrinos e dos forasteiros. Estas figuras poderiam nos remeter à imagem de personagens marginalizados. Mas, ao mesmo tempo, elas nos remetem a personagens caracterizados pela mobilidade: peregrinos e forasteiros são homens e mulheres que circulam e se deslocam. Ambos são, na hagiografia, símbolos de uma propriedade dinâmica na qual o posto de detentor do bem deveria ser ocupado por figuras que se deslocavam, revezavam ou modificavam. Assim como o bem deveria circular dentro do grupo, as pessoas também deveriam estar em movimento. Sem que ocorra a circulação, a posse é desautorizada.

Esta ideia reaparece em outros trechos. Como quando Celano (2008 IN: FONTES FRANCISCANAS E CLARIANAS, p. 340) descreve Francisco alertando seus companheiros que não "habitassem qualquer eremitério, se não constasse certo o dono a quem pertencia à 
propriedade". Incentivando os irmãos da Ordem a seguirem na solidão e sem nada pertencer. Mas Celano (IN: FONTES FRANCISCANAS E CLARIANAS, p. 340) finaliza o trecho sinalizando algo importante: Francisco, na narrativa, afirma que os frades não poderiam "viver sem o uso de casas". A palavra chave é uso. A hagiografia não descarta a noção de propriedade: o trecho revela uma preocupação em encontrar uma definição adequada de um exercício da propriedade, de modo a não ferir os votos de pobreza e de desapego material.

Esta constatação é interessante e permite uma inferência: o argumento tal como formulei reforça uma concepção de propriedade cujas feições estão mais próximas da modernidade do que do primitivismo. Ao utilizar a teoria de Polanyi, não gostaria de incorrer na ideia de que os frades podem ser simplesmente "primitivizados". Ao usar os referenciais do primitivismo econômico, busco respostas para pensar possibilidades das relações materiais do movimento minorita, me atentando para a própria complexidade das relações socioeconômicas. Uma teoria - assim como a fonte documental - não é um quadro esquemático e pronto de antemão cuja aplicabilidade ocorre em termos de simples transposição. É necessário atentar para a tensão dialética ante o modelo (teoria) e a realidade.

Se fosse possível estabelecer um paralelo entre as trocas ocorridas no sistema capitalista e aquelas que se desenvolvem em sistemas anteriores ao seu advento é possível perceber algumas diferenças; por exemplo, segundo Polanyi (2008) este novo sistema 
social tornou os indivíduos "átomos dispensáveis", sem maiores impedimentos e regulações, como pregavam os liberais, era excitá-lo a ser um moedor de carne ou um "moinho satânico", como ele preferiu, destruindo todas as relações sociais. A emancipação do que hoje chamamos de econômico das regras morais graças à separação radical deste aspecto do conjunto do tecido social se deu graças à existência de um mercado auto regulável e que seria a fonte do sistema e que se constituiu em uma inovação que deu origem a uma civilização específica $^{14}$.

${ }^{14}$ Uma tal instituição não poderia existir em qualquer tempo sem aniquilar a substancia humana e natural da sociedade, ela teria destruído fisicamente o homem e transformado seu ambiente em um deserto. Inevitavelmente, a sociedade teria que tomar medidas para se proteger, mas, quaisquer que tenham sido estas medidas elas prejudicaram a auto-regulação do mercado, desorganizariam a vida industrial e, assim, ameaçariam em mais de uma maneira (POLANYI, p.18, 2008). O nascimento da autonomia econômica seria assim a explicação da ascensão da "civilização oitocentista"; sua queda estaria no colapso do sistema internacional, já que o equilíbrio de poder não poderia assegurar a paz, "uma vez fracassada a economia mundial no qual repousava" (POLANYI, p.18, 2008). O mercado autoregulavel foi demolido "pela concentração capitalista e pela representação organizada do trabalho, pela inevitável defesa social contra o mecanismo do mercado, pelo protecionismo e pelo imperialismo" (POLANYI, 2012, p. 21). A crise do capitalismo liberal deixou claro que a economia já não podia funcionar sem um controle consciente. A crise "forçou" a busca por uma nova organização social. Polanyi se inclinou a tendências socialistas derivadas da ideia de "democracia industrial" e do "socialismo funcional" de Otto Bauer. No entanto, segundo Micheli Cangiani (POLANYI, 2012), quando escreveu sua obra, a crise institucional não deu origem a uma economia socializada, tal como por ele idealizada, mas sim ao facismo e a guerra mundial. O objetivo de Polanyi, ao escrever o livro, foi explicar a origem desses resultados pavorosos e tornar a levantar a questão da politica moderna, entendida como a tendência para controle democrático dos processos sociais - e do processo econômico, em primeiro lugar. Desse modo, a liberdade dos indivíduos poderia se realizar plenamente através de sua responsabilidade política (POLANYI, 2012, p. 24). O tom que marca o final da obra deixa claro o seu clamor pelo ideal de liberdade que fora denegrido em prol de uma mera defesa da livre inciativa. A "separação institucional" oitocentista entre as esferas

Revista Vernáculo n. ${ }^{\circ} 43$ - primeiro semestre/2019

ISSN 2317-4021 
Mas talvez a mais importante seja a equivalência daquilo que é trocado. Ou em outras palavras, os mecanismos que de forma simples estabelecem relações quantitativistas entre bens de diferentes tipos. Não se trata do valor do objeto em si, como no caso descrito por Celano. Nesta sociedade o que determina é a tradição e o costume. As trocas ou as relações de reciprocidade não ocorriam sem um parâmetro: o da satisfação das necessidades materiais.

\section{II}

As hagiografias minoritasestão entre os documentos históricos que deixaram de ser considerados inaptos a pesquisa (por representarem uma ideologia e não cumprirem com os rigores científicos requisitados pela história científica) e passaram a ser entendidos como a construção textual de um grupo, com finalidade de legitimar uma crença, e portanto, importantes fontes sobre o próprio grupo e o momento histórico dessa construção.

econômicas e politicas terminou num período de crise e "equilíbrio de poder" entre as classes, que acabou levando, com o fortalecimento da classe dominante, ao solapamento da democracia, mesmo onde o facismo não prevalecia (POLANYI, 2012, p. 27). O argumento é sedutor. A saída encontrada por Polanyi para a crise - apesar de não se concretizar - oferece respostas interessantes ao fracasso da economia capitalista naquele momento. Mas, devemos nos atentar a dois pontos. Duas críticas, se se preferir: primeiramente, a alternativa assim teorizada a partir da busca pelo modelo socialista não poderá ser integralmente transposta para a análise de uma sociedade altamente hierarquizada - como a medieval, nosso contexto de investigação. E em segundo lugar, o discurso polanyiano exagera na liberdade do individuo como ação economicamente orientada. Tendo em vista estes cuidados, poderemos prosseguir.

Revista Vernáculo n. ${ }^{\circ} 43$ - primeiro semestre/2019

ISSN 2317-4021 
São exemplos de textos que por muito tempo permaneceram às margens das críticas modernas da historiografia por se tratarem de escritos permeados por referencias religiosas, sagradas e sobrenaturais. Cada aspecto da vida do biografado é perpassado por alguns desses referenciais, o que fez com que os historiadores tenham se afastado destes textos visto que os mesmos invalidariam análises mais profundas.

A abordagem que propus neste artigo procura ler as narrativas hagiográficas como documentos capazes de revelar as intrincadas camadas de valores partilhadas por sujeitos históricos e, por isso, transmitidas por eles na forma de textos. Os principais valores identificados e analisados foram identificados em episódios que tinham em comum: práticas idealizadas de troca e de reciprocidade. Tais práticas, ainda que jamais tenham ocorrido, retravam princípios de condutas que os sujeitos veicularam como exemplos a serem imitados. Nestes princípios encontramos a mobilidade dos bens por meio da troca, da caridade e da esmola como uma razão capaz de autorizar a posse temporária destes mesmos bens - ou seja, uma forma de propriedade. Além disso, a circulação e a transitoriedade do uso implicavam certa noção de invidualismo, não uma noção moderna ou revolucionária, mas que legitimava a afirmação de sujeitos particulares e do próprio grupo a que pertenciam.

Retomando o trabalho de Marcelo Cândido (2014), no qual existe um capítulo dedicado ao roubo na hagiografia, o objetivo de seu 
livro é precisamente revelar uma "economia dos qualitativos jurídicos" da sociedade da Alta Idade Média. Exercício de análise que adoto como modelo de inspiração e que se mostrou útil, sobretudo, para elucidar a forma normativa da noção de propriedade entre os frades minoritas. Não se tratava, como demonstrou Marcelo Cândido para a sociedade merovíngia, de uma posse divina. Nas narrativas franciscanas, não é Deus o proprietário último dos bens, mas os próprios homens: agentes da pobreza neste mundo. O movimento franciscano partilhava $\mathrm{e}$ legitimava uma relação de propriedade: móvel, circulante e fraterna.

\section{Bibliografia}

CONTI, Martino. Estudos e pesquisas sobre o franciscanismos das origens. Petrópolis: Vozes, 2004.

D'ALENÇON, Edouard. FrancisciAssisensis: vitaetmiracula, additisopusculisliturgicis, auctore Fr. Thoma de Celano. Roma, Desclée: 1906.

DUBY, G. Idade Média na França: de Hugo Capeto a Joana D'arc (987 - 1460). Rio de Janeiro: Jorge Zahar, 1992.

BASCHET, Jérome. A civilização feudal: do ano 1000 a colonização da América. São Paulo: Globo, 2006.

DELUMEAU, Jean. História do medo no Ocidente, 1300-1800. São Paulo: Companhia das Letras, 1993.

FRUGONI, C. A vida de um homem: Francisco de Assis. São Paulo: Companhia das Letras, 2011.

GUERREAU, A. El futuro de um passado. Barcelona: Critica 2002. 
LE GOFF, Jacques. São Francisco de Assis. Rio de Janeiro: Editora Record, 2001.

LE GOFF, Jacques \& SCHMITT, Jean-Claude. Dicionário Temático do Ocidente Medieval. Bauru: Edusc, 2006.

MIATELLO, André Luís Pereira. Santos e pregadores nas cidades medievais italianas: retórica cívica e hagiografia. Belo Horizonte: Fino Traço, 2013.

PELTIER, A.C. S. R. E. S. Bonaventurae Opera Minorum. Paris: L. Vivès, 1868, vo. XIV.

PIPES, Richard. Propriedade e liberdade. Rio de Janeiro: Record, 2001.

POLANYI, Karl. A subsistência do homem e ensaios correlatos. Rio de Janeiro: Contraponto, 2012

SABATIER, Paul. Vida de São Francisco de Assis. Bragança Paulista. Editora Universitária São Francisco: Instituto Francisco de Antropologia, 2006.

SESSA, Kristina. The formationof papal authority in late antiqueItaly. New York: Cambridge, 2013.

SILVA, Marcelo Candido da. Uma história do roubo na Idade Média: bens, normas e construção social no mundo franco. Belo Horizonte: Fino Traço, 2014.

VAUCHEZ, André. Espiritualidade na Idade Média Ocidental século VIII a XIII. Rio de Janeiro: Jorge Zahar Editora, 1995.

Recebido em 03/07/18 aceito para publicação em 22/01/19

Revista Vernáculo n. ${ }^{\circ} 43$ - primeiro semestre/2019

ISSN $2317-4021$ 